\title{
MUJERES, CIUDADANÍA Y GLOBALIZACIÓN *
}

\author{
Isabel Turégano \\ Universidad de Castilla-La Mancha
}

RESUMEN. El proyecto emancipatorio de las mujeres sigue siendo necesario para contribuir a la formulación de un nuevo modelo cultural y político. El trabajo pretende delimitar el alcance y confines de tal proyecto en el contexto de las transformaciones sociales contemporáneas. Se defiende, en primer lugar, que debe ser un proyecto multilateral cuyo discurso práctico, concebido no como una idealización abstracta sino como experiencia histórica, aproveche las oportunidades y posibilidades que brinden los distintos niveles de participación política. En segundo lugar, debe ser un proyecto propio, construido desde la resignificación de los legados culturales dominantes, pero alejado de un modelo identitario cerrado y autónomo que impida atender a los modos específicos en que las relaciones de género se construyen y reproducen en contextos diferentes. Y, por último, su carácter multilateral no debería implicar un pluralismo desjerarquizado, en el que las distintas sedes de participación se desarrollen autónomamente conforme a lógicas diversas, sino que debería aprovechar cada instancia de participación para reforzar y complementar los déficits funcionales y de legitimación de las otras instancias conforme a un modelo normativo común.

Palabras clave: feminismo, globalización, nación, Estado, ciudadanía.

ABSTRACT. The emancipatory project of women is still required to contribute to the formulation of a new cultural and political model. This paper aims to define the scope and boundaries of that project in the context of contemporary social transformations. It is defended, firstly, that it should be a multilateral project, which practical discourse, conceived not as an abstract idealization but as historical experience, takes advantage of the opportunities and possibilities that provide different levels of participation. Secondly, it should be an independent project, constructed from the resignification of dominant cultural legacies. But a project away from closed and autonomous identitarian models which prevent address the specific ways in which gender relations are constructed and reproduced in different contexts. And, finally, its multilateral character should not imply a non-hierarchical pluralism, in which different spheres of participation are developed independently according to different logics. It should take advantage of each domain of participation to strengthen and complement the functional deficits and legitimacy of other spheres under a common normative model.

Keywords: feminism, globalization, nation, State, citizenship.

\footnotetext{
* Fecha de recepción: 22 de noviembre de 2011. Fecha de aceptación: 18 de diciembre de 2011.
} 


\section{PLANTEAMIENTO}

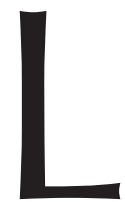

os movimientos de mujeres y la teoría feminista no han sido nunca proyectos teóricos y emancipatorios estáticos. Sus demandas y propuestas han sufrido enormes cambios y diversificaciones con los que han ido adaptando el discurso a nuevas necesidades y formas de superar la discriminación. Las complejas transformaciones que vivimos en las últimas décadas no han podido resultar ajenas al análisis y la crítica de las mujeres, cuyo proyecto igualitarista sigue viéndose postergado en aras de prioridades sociales y económicas que impiden avanzar hacia la efectiva igualdad.

El presente trabajo se plantea críticamente el sentido de algunas de las cuestiones que la teoría feminista ha analizado en relación con la cuestión de los límites o alcance de su discurso. La cuestión de las fronteras o los límites del discurso tienen en nuestros días una especial relevancia no sólo en relación con las causas de las nuevas formas de injusticia sino también respecto del contexto en el que debemos buscar las posibles soluciones. Como señaló N. FRASER, las cuestiones relativas al «marco idóneo» de una teoría de la justicia son necesarias, frente a modelos que se han centrado en las cuestiones sustantivas. La determinación de los límites es una cuestión trascendental previa al análisis de las reivindicaciones sobre distribución, reconocimiento y representación política ${ }^{1}$. Por ello, conviene detenerse a repensar hacia dónde se dirigen las críticas de las mujeres y qué alcance tienen sus propuestas.

El trabajo se vertebra en torno a la respuesta a tres cuestiones entrelazadas. La primera se plantea si los proyectos sociales de las mujeres tienen los mismos límites o confines que los de los hombres o son, en esencia, más locales o globales, como alternativa al alcance nacional que han tenido prioritariamente los modelos conocidos dominados por varones. La segunda se orienta a analizar hasta qué punto comparten o pueden compartir las mujeres el mismo proyecto nacional que los hombres, o, dicho de otro modo, cuál es el papel de las mujeres en la construcción cultural de la nación. Por último, el trabajo se cuestiona si las profundas transformaciones sociopolíticas operadas por la globalización son la ocasión idónea para una reinterpretación de la ciudadanía en un sentido complejo que resulte más inclusivo para las mujeres.

Las respuestas a cada una de las cuestiones muestran que el feminismo ha tratado en muchas ocasiones de lograr un equilibrio difícil entre la exigencia de una comunidad global de discurso y la atención a las realidades concretas de desigualdad de poder, que condicionan el alcance de su crítica. La pretensión feminista de reconceptualizar la teoría ética y política sobre la base de la diferencia o la pluralidad y la necesidad de contextualizar el debate conduce a modelos particularistas y escépticos desde los que se rompen las bases para una crítica feminista genérica. La tendencia parece ser hacia una práctica feminista más que una teoría propiamente dicha, orientada por fines u objetivos igualitarios. Lo que puede suponer una limitación de su proyecto emancipatorio, que no puede agotarse en la crítica sino que debe tender a formular proyectos alternativos de formalización de nuevos sujetos políticos y garantías efectivas de derechos.

\footnotetext{
1 N. Fraser, 2005.
} 
Por otra parte, las respuestas revelan el carácter mutuamente complementario de la lucha en el ámbito político y el ámbito simbólico y la insuficiencia de avanzar sólo en uno de ellos al margen del otro: los problemas derivados de la globalización neoliberal y sus efectos no pueden resolverse al margen de la dimensión ideológica de desvalorización de las mujeres que les sustrae del ejercicio efectivo de sus derechos. La propuesta de modelos políticos integradores no puede hacerse al margen de una resignificación cultural.

\section{2. ¿LOCAL, NACIONAL O GLOBAL?}

La primera cuestión que surge en torno al alcance del pensamiento y el movimiento de las mujeres es la relativa a si sus proyectos sociales tienen los mismos límites que los de los hombres o se plantean esencialmente en una dimensión distinta. El feminismo tiene un significativo componente transnacional, en la medida en que sus demandas son válidas y pertinentes por encima de las fronteras estatales. La situación de opresión, subordinación y desigualdad de las mujeres tiene características similares en todas las sociedades y en todos los momentos, a pesar de sus diferencias nacionales, étnicas o económicas. La crítica feminista no es específica de una nación o etnia, sino que hace referencia a un tipo de dominación y subordinación que comparten diferentes naciones y diferentes grupos sociales.

Ante la deficiente inclusión de las mujeres en la igualdad jurídica de los Estados, el feminismo ha sido consciente de la necesidad de aprovechar los espacios transnacionales para la acción y ha trabajado por consolidar asociaciones y alianzas al margen de las fronteras. Las organizaciones y centros internacionales y, en general, las redes feministas transnacionales han producido un complejo entramado global para la denuncia y la crítica y han respaldado una diversidad de Organizaciones no Gubernamentales particularmente preocupadas por atender las necesidades de las mujeres. Desde la segunda posguerra, este activismo feminista transnacional asume la vulnerabilidad del Estado y su responsabilidad ante instancias internacionales.

El feminismo ha sido muy activo en la consecución de una normativa internacional garantista. La década de los noventa fue la década de las mujeres en las Naciones Unidas, en la que se adoptaron la Declaración de Derechos Humanos de Naciones Unidas de Viena (1993), donde se afirmaba que «los derechos humanos de la mujer y de la niña son parte inalienable, integrante e indivisible de los derechos humanos universales» (apartado 18), la Conferencia de El Cairo sobre Población y Desarrollo (1994) y la Declaración de Pekín de 1995 que marcó un hito en la acción social del feminismo internacionalista. También la presión de los movimientos feministas ha influido en la normativa y decisiones de las instituciones de la Unión Europea, que ha asumido como uno de sus principios fundamentales la garantía de la igualdad de oportunidades y la lucha contra las discriminaciones persistentes en el ámbito privado, económico y político.

Pero, en cierto sentido, si las mujeres han orientado gran parte de su actuación hacia la búsqueda de espacios y garantías internacionales ha sido por la incapacidad y debilidad del Estado en proporcionárselos. Al sesgo patriarcal del Estado desde su 
formación se añaden los problemas derivados de la crisis actual de las instituciones estatales que aparecen impotentes ante la creciente privatización del poder de toma de decisiones y las dificultades para realizar autónomamente sus funciones tradicionales. Muchos de los rasgos de los actuales procesos de cambio contribuyen a limitar los más recientes avances en la plena igualdad de hombres y mujeres. Así, la crisis del modelo de bienestar, es decir, precisamente de aquellas funciones del Estado que las movilizaciones feministas más reclamaron; la subrepresentación de las mujeres en la sociedad civil y en las instituciones políticas; el auge de los movimientos éticos y religiosos fundamentalistas que dominan la política de algunos Estados; la privatización de lo público, etc. En este sentido, puede pensarse que los esfuerzos por fortalecer la eficacia y legitimidad del Estado, y no sólo la búsqueda de espacios alternativos de acción, pueden contribuir a la igualdad ante la incertidumbre del contexto supranacional.

La afirmación del carácter internacional del movimiento feminista parte, al mismo tiempo, de una percepción excesivamente negativa del papel del Estado y un desproporcionado optimismo respecto del derecho internacional. La apelación al mismo como alternativa al Estado deslegitimado e incapaz se hace en muchas ocasiones desde un uso normativo del término como expresión de un ideal de organización política. El derecho internacional aparece, como escribe KOSKENNIEMI, menos como una regla o una institución que como apoderado del vocabulario de la justicia y la bondad, la solidaridad, la responsabilidad y la $\mathrm{fe}^{2}$. El autor sostiene en su conocido From Apology to Utopia que, en realidad, el derecho internacional se mueve dentro de una contradicción o dicotomía fundamental entre el comportamiento, voluntad e intereses concretos de los Estados y la necesidad de la determinación y aplicación imparcial de sus normas que, al margen de comportamientos, voluntades o intereses, no dejan de ser mera moralidad. En este sentido, el derecho internacional se presenta como instrumento jurídico-político para la búsqueda de una comunidad global de valores ${ }^{3}$.

Podría pensarse que esa concepción normativa de la legalidad internacional hace irrelevante el análisis crítico de su contenido y funcionamiento. Pero hace ya un par de décadas que las teóricas feministas han venido denunciando el carácter ideológico del derecho internacional, que encubre bajo su imparcialidad discriminaciones que perduran. Los esfuerzos de las organizaciones de mujeres en la acción internacional han tenido escaso efecto en los procedimientos, instituciones y acciones internacionales, cuyos esfuerzos en favor de la seguridad internacional, la autodeterminación de los pueblos o la desaparición de la discriminación étnica no han tenido en cuenta la añadida posición de desventaja de las mujeres en tales realidades. La crítica feminista al derecho internacional continúa la crítica genérica a las pretensiones de imparcialidad y neutralidad del derecho que ocultan la perspectiva y experiencia de los varones, dada la desigual participación de hombres y mujeres en las instituciones de creación y aplicación del derecho y la consiguiente desatención a la situación y necesidades de éstas. La prioridad otorgada por el derecho internacional a los problemas políticos y de seguridad sobre las cuestiones sociales y económicas deja de lado el contexto de condiciones desigualitarias que impide la realización efectiva de los derechos de muchas

\footnotetext{
2 Koskenniemi, 2007: 30.

Koskenniemi, 2005.
} 
mujeres ${ }^{4}$. Y, como afirman D. Buss y A. MANJI, si el derecho internacional está sesgado estructuralmente, la tarea de las mujeres no es la de ser incorporadas a una normativa internacional parcialmente reformada, sino la de una reestructuración más profunda que revise sus categorías fundamentales, empezando por la idea de responsabilidad estatal ${ }^{5}$.

Aún habría que añadir algunas matizaciones adicionales al internacionalismo del movimiento feminista: en primer lugar, gran parte de la participación cívica de muchas mujeres se desenvuelve en el nivel local, implicándose en organizaciones comunitarias y movimientos sociales generados en torno a creencias comunes y proyectos particulares compartidos. Estos modelos comunitarios son relevantes no sólo por los beneficios sociales que generan sino también por el reforzamiento que suponen del capital social. Particularmente en el caso de las mujeres, el activismo local aumenta su confianza al percibirse como actoras políticas y ciudadanas efectivas ${ }^{6}$. Al mismo tiempo, las pequeñas comunidades de creencias y valores compartidos proporcionan apoyo emocional para el disenso y la resistencia al discurso hegemónico sentando las bases para plantear modelos alternativos. En segundo lugar, desde la pluralidad étnica y nacional se ha acusado a la teoría feminista de ser un producto de la ideología occidental y, como tal, inválido para representar la diversidad de realidades de las mujeres, lo que plantea la dificultad de un discurso feminista global.

En realidad, la relación del género con las distintas instancias de participación política no es siempre igual ni uniforme sino que depende de múltiples factores históricos relativos al grado de identificación de la ciudadanía con las instancias formales, las transformaciones de los Estados o la formación y efectividad de las instituciones supranacionales ${ }^{7}$. Ello es consecuencia de que el feminismo trata de conseguir un equilibrio difícil entre la exigencia de una comunidad global de discurso y la atención a las realidades concretas de desigualdad de poder, concibiendo el discurso práctico no como una idealización abstracta sino como experiencia histórica con consecuencias reales y, por tanto, condicionado por los factores sociales existentes ${ }^{8}$.

\section{GÉNERO Y NACIÓN}

La relación de las mujeres con el nacionalismo ha sido compleja y contradictoria. Al tiempo que el feminismo se vinculó al proyecto nacional moderno como proceso de reconocimiento de derechos y de igualación social, ha visto cómo la necesidad de articular sus demandas conforme a los parámetros nacionalistas ha distorsionado y alterado sus reivindicaciones. Los movimientos feministas y nacionalistas han trabajado

4 Tras el creciente aumento de análisis feministas del derecho internacional durante los años noventa, uno de los primeros estudios que trataron de ofrecer una crítica global fue el de H. CHARLESWORTH y Ch. CHInkin, The Boundaries of International Law: A Feminist Analysis, Manchester, Manchester University Press, 2000. Desde entonces, han proliferado los análisis en clave feminista de los temas y conceptos centrales de las relaciones internacionales, cuyo análisis excedería los límites de este trabajo.

5 BuSS y MANJI, 2005: 2.

6 LISTER, 1997: 32.

7 WALBY, 1992: 81 y ss.

8 JAGGAR, 1998: 7-31. 
juntos en la construcción de muchos proyectos nacionales, en los que las mujeres han luchado por definir, al mismo tiempo, sus derechos para ese contexto. Las mujeres quieren ser partícipes en la construcción de la nación: no aparecer simplemente como víctimas o receptoras pasivas del sistema?.

El carácter complejo y contradictorio de la relación entre feminismo y nacionalismo se aprecia con claridad en los procesos de nacionalización poscoloniales de finales del XIX y comienzos del $\mathrm{XX}^{10} \mathrm{o}$ en las más recientes revueltas democratizadoras del mundo árabe. Los primeros estuvieron marcados por una tensión entre las tendencias nacionalistas modernas y liberales, que promovieron la expansión de los derechos de ciudadanía de las mujeres y la igualdad social, y las tendencias organicistas, antimodernistas que, preocupadas con el imperialismo de Occidente y la contaminación de los valores identitarios de sus comunidades, obstaculizaron los cambios en las relaciones de género. En la mayoría de los casos, la descolonización ignoró los derechos de las mujeres que lucharon junto a los independentistas para la consecución de un nuevo orden social. Como entonces, también ahora, las mujeres han participado activamente en las revueltas de la denominada «primavera árabe» para cambiar las estructuras de poder tradicionales, aumentando su presencia y visibilidad en el espacio público, y han vuelto a verse relegadas después de los círculos y centros de decisión, persistiendo su dependencia de estructuras patriarcales públicas y privadas ${ }^{11}$.

No obstante, el propio feminismo no tiene un modelo común de emancipación y participación de las mujeres, resistiéndose desde planteamientos culturalistas y diferencialistas a concebirlo conforme a los modelos morales y culturales del Occidente imperialista ${ }^{12}$. En mi opinión, estas críticas culturalistas yerran en el nivel al que han de dirigir su oposición, que no es tanto el del discurso normativo cuanto el nivel de la práctica social y política efectiva, y, al confundirlo, refuerzan la legitimación de las tesis identitarias y comunitaristas que subordinan los derechos de las mujeres a otros intereses sociales (como la paz social, el respeto a la diversidad, el desarrollo económico, entre otros $)^{13}$. La igualdad entre hombres y mujeres y su igual capacidad de participación no son sólo un legado histórico occidental sino exigencias normativas cuyas raíces pueden encontrarse en doctrinas muy diversas. Desde un feminismo universalista se niega que el movimiento de las mujeres sea, sin más, una construcción occidental que distrae de la lucha por la liberación política y económica y se considera, por el contrario, que las circunstancias históricas que generan condiciones para avanzar en la democratización y desarrollo de las sociedades deben ser igualmente aprovechadas para avanzar en la igualdad ${ }^{14}$. Se trata de aprovechar las oportunidades que ofrece la realidad social

9 WEST, 1997: xi-xxxvi.

10 JAYAWARDENA, 1986; KANDIYOTI, 1991: 429-443.

11 Igual que ahora, en 1791, en réplica a la Declaración de los derechos del hombre y el ciudadano, O. DE GOUGES escribía: «El hombre esclavo ha redoblado sus fuerzas y ha necesitado apelar a las tuyas para romper sus cadenas. Pero una vez en libertad, ha sido injusto con su compañera. ¡Oh, mujeres! ¡Mujeres! ¿Cuándo dejaréis de estar ciegas? ¿Qué ventajas habéis obtenido de la Revolución? Un desprecio más marcado, un desdén más visible...» (O. DE GOUGES, 1791).

12 Ahmed, 1984; Mernissi, 1985; El SAADAWI, 1988.

13 En este sentido, TAMZALI, 2011.

14 En este sentido, autoras como JAYAWARDENA han puesto de manifiesto que los relevantes cambios materiales e ideológicos que trajo la descolonización (expansión del capitalismo e incorporación de las mujeres a trabajos asalariados, apertura de la educación a amplios sectores de la población, migraciones del campo a las 
para construir un modelo de democracia y un modelo económico que mantenga la alianza positiva de hombres y mujeres. La eliminación de las desigualdades de género es necesaria para un desarrollo humano, social y económico sostenible a nivel mundial, la vía para el progreso no sólo de las mujeres sino también de las comunidades en las que se integran.

Así, las mujeres no se identifican con cualquier proyecto nacional sino con aquel en cuya construcción hayan podido participar. Si empleamos la idea de ANDERSON de la nación, no como una realidad abstracta, sino como comunidad imaginada y construida, que puede ser reinventada, las narrativas y culturas que constituyen el sustrato del discurso nacionalista no son fenómenos estáticos e involuntarios, sino procesos sociales dinámicos en los que diferentes voces llegan a ser más o menos hegemónicas en su interpretación del mundo.

Las mujeres han constituido más bien símbolos pasivos de la tradición cultural de la nación que han contribuido a la estabilidad y la reproducción social, representando la unidad y el honor de la colectividad. Su contribución se limita a la definición de la identidad étnica, religiosa o nacional de una comunidad, al mismo tiempo que se les niega su capacidad de actuar y decidir. Como señala ANDERSON, el nacionalismo hace uso de términos vinculados con el parentesco o el hogar para denotar el modo en que estamos naturalmente vinculados a la comunidad. La asociación tradicional de la mujer con el ámbito privado al que se vinculan tales términos refuerza su imagen como símbolo de la nación en su identidad de madres y pilar de una familia refugio frente a las incertidumbres de lo público (la Madre Rusia, La Patria de la Revolución Francesa, la fertilidad de la Madre Tierra). El honor de la colectividad también se refleja en la mujer: los crímenes de honor, la lapidación, las desfiguraciones del rostro de las mujeres o la violación masiva de mujeres en tiempos de guerra. Más que como símbolos del cambio, la retórica nacionalista ha concebido a las mujeres como portadoras de la tradición y garantes de la esencia cultural de la nación (p.e. la práctica de imponer el velo para marcar los límites simbólicos de la comunidad cultural y religiosa o la de prohibir las relaciones sexuales o el matrimonio con hombres de otros grupos o religiones). De ahí, la obligación que les oprime de portar los símbolos de su pertenencia a la comunidad. Símbolos que son utilizados por los movimientos nacionalistas y comunitaristas contra los intentos de dominación. Los mayores avances institucionales y cambios jurídicos a favor de la igualdad conviven en nuestros días con fenómenos como la violencia doméstica o las peores condiciones laborales o salariales de las mujeres.

De este modo, las mujeres se encuentran incluidas en la esencia identitaria de la comunidad pero excluidas de la posibilidad de decidir cómo haya de entenderse esa identidad. De forma que la apelación al respeto a las reivindicaciones culturalistas e identitarias por sí mismo, sin cuestionar las dominaciones subyacentes, subvierte el discurso feminista. No obstante, evitarlo no implica necesariamente eludir el lenguaje de las culturas y las diferencias que ha sido el discurso propio de muchas aportaciones feministas. Lo que resulta preciso eludir desde el feminismo es la tesis multiculturalista para la que las culturas son totalidades de sentido que son inconmensurables.

ciudades, etc.) favorecieron la transformación de instituciones y costumbres que mantenían subyugadas a las mujeres a requerimientos éticos y religiosos discriminatorios. El cambio que se operó en las relaciones entre hombres y mujeres evocaba simbólicamente el cambio operado por la nueva nación. 
Pero las culturas no son realidades homogéneas y estáticas, sino procesos sociales cambiantes, internamente divididos e incoherentes, en los que diferentes voces discrepantes compiten por definir un relato que llegue a ser hegemónico. La homogeneización cultural no es sino el resultado de la hegemonía del proyecto de algunos agentes sociales que logran mostrar una coherencia interna e imponerla sobre el resto de proyectos. El primer paso hacia un modelo integrador y no impuesto, supuso para las mujeres plantear en sentido crítico su propia alteridad, mostrándose como voces disidentes que ambicionan un proyecto cultural y nacional diferente. En cierto sentido, las mujeres pueden concebirse ajenas al proyecto colectivo que encarna la nación en cuanto que su posición se ha construido sobre la diferencia, identificándose con la imagen del «otro» al que las tradiciones colectivas, las normas y el sentido común tratan con reglas diferentes a las de la generalidad de la colectividad en la que viven.

En 1938 Virginia Woolf planteaba en su obra Tres Guineas cómo ante las emociones patrióticas de los hombres la mujer se pregunta «¿Qué significa para mí la patria, siendo como soy una extraña?» y para contestar «analizará el significado que el patriotismo tiene en su caso. Se informará de la posición ocupada por sus compañeras de sexo y de clase, en el pasado. Se informará de la cuantía de tierras, riquezas y propiedades en posesión de sus compañeras de sexo y clase en el presente, es decir, de la cuantía de la parte de «Inglaterra» que le pertenece». Y la «extraña dirá: Durante la mayor parte de su historia, nuestra patria me ha tratado como a una esclava, me ha denegado la educación y el compartir posesiones patrias... Y así es por cuanto, en mi condición de mujer, no tengo patria. En mi condición de mujer, no quiero tener patria. En mi condición de mujer, mi patria es el mundo entero» ${ }^{15}$.

El extraño, en la concepción de SIMMEL, se define como una síntesis entre proximidad y distancia, participa de la vida del grupo pero se mantiene como una figura externa ${ }^{16}$. Frente a la imagen del extranjero que está más allá de las fronteras externas, el extraño se define por las fronteras internas del grupo de cuyas categorías generales se encuentra excluido pero que marcan, no obstante, los límites de sus obligaciones y responsabilidades sociales. Las tensiones entre la colectividad y el extraño derivan de que éste supone un desafío al marco común de significados y categorías asumidos que cohesionan el grupo en su afán por reinterpretarlos y cambiarlos. Y de esa tensión deriva el papel del extraño como factor de innovación social y cultural. H. BHABHA habla de las «contranarrativas» que emergen en los márgenes de las naciones que alteran los significados y fronteras internas de las comunidades ${ }^{17}$.

Una concepción dinámica de la cultura permite asumir las diferencias sin caer en la disyuntiva entre el asimilacionismo o la coexistencia de múltiples identidades definidas y delimitadas. Desde esta perspectiva, la inclusión de las diferencias en el proyecto hegemónico, que reclaman los movimientos emancipatorios, habrá de ser el resultado de la hibridación del legado cultural de las diversas partes, una recreación progresiva de las culturas humanas que borre las fronteras internas imaginarias. $\mathrm{H}$.

\footnotetext{
15 WoOLF, 1980: 146-148.

16 SIMMEL, 1977: vol. II, 716-722.

17 Vid. ВНавНа (ed.), 1990; ВНавНА, 1994.
} 
BHABHA dice que el encuentro cultural crea un sentido de lo nuevo como un «acto insurgente de traducción cultural» ${ }^{18}$. De este modo, la inclusión en un proyecto común y la continuidad de las particularidades culturales no tienen por qué ser mutuamente excluyentes ${ }^{19}$. Esta vía propuesta, entre otros, por S. BENHABIB trata de mostrar que el universalismo puede ser sensible a las diferencias si abandona el cielo de las abstracciones y se compromete con nuestras múltiples y complejas identidades, situándose en una posición intermedia entre la tesis de la inconmensurabilidad de las culturas y valores plurales y la tesis de un consenso teórico superpuesto. La pretensión universalista ha de aspirar a la continua expansión del «nosotros» a medida que vaya incorporando al mayor número posible de extraños mediante una experiencia cada vez más ampliada. El interés por lo universal es complementario con el interés por las prácticas y creencias que otorgan significado a las vidas humanas particulares y diferentes ${ }^{20}$.

Desde esta perspectiva, creo que las mujeres no deberían tender a forjar un modelo identitario como totalidad holística y separada que defina autónomamente las fronteras y fines del colectivo de mujeres. Por el contrario, tales relatos deberían unirse en la producción de nuevas narrativas capaces de servir de base a una cultura política común. El género no puede convertirse en una construcción abstracta referida a una identidad coherente común. Las explicaciones abstractas y universales de la subordinación de las mujeres pueden distraer la atención de los modos específicos en que las relaciones de género se construyen y reproducen en diferentes sociedades. En las situaciones concretas, la opresión de las mujeres se entremezcla y articula con otras formas de opresión social y divisiones sociales. No todas las mujeres son oprimidas o subyugadas del mismo modo y con el mismo alcance. En consecuencia, la rígida separación entre problemas de redistribución y problemas de reconocimiento distorsiona la relación dinámica entre los conflictos económicos, ideológicos e identitarios ${ }^{21}$ : las identidades culturales o de género no predeterminan las demandas políticas y sociales en la esfera pública. La superación de la discriminación de las mujeres implica no sólo un cambio en los patrones culturales sino también, y fundamentalmente, una reestructuración de las relaciones socioeconómicas y políticas. Su proyecto no es un proyecto identitario sino ético y político.

18 BНАВНА, 1994: 70.

19 BENHABIB, 2006.

20 APPIAH, 2005. Es interesante la propuesta de A. NAJMABADI en la línea de la propuesta de APPIAH de la preferencia por lograr acuerdos sobre reglas o prácticas particulares sin aspirar a la búsqueda de un consenso sobre su fundamentación, lo que permite minimizar el conflicto y alcanzar decisiones comunes. NAJMABADI habla de la cooperación en cuestiones específicas sin realizar demandas generales sobre la igualdad o los derechos de las mujeres (citada en N. YUVAL-DAVIS, 1997: 124. La autora también cita como defensora de un argumento similar a H. AFSHAR, 1994: 15-21). YUVAL-DAVIS pone como ejemplo el caso de la abogada sudafricana que sugirió un modo de acabar con la poligamia sin revelarse directamente contra ella. Su propuesta era que la práctica tradicional de la poligamia no debía ser abolida jurídicamente, sino que debería disponerse jurídicamente que en el matrimonio la mujer tiene derecho al 50 por 100 de la propiedad de la pareja, de modo que si el marido contrae matrimonio después, sólo podrá compartir con la nueva esposa el 50 por 100 que le corresponde, y así sucesivamente (Ibid., 123-124). Algunas feministas islamistas temen que estas posiciones que no cuestionan el marco de fundamentación cultural y religiosa de sus comunidades pueden contribuir a su legitimación.

21 BenHABIB, 2006: 47-55; OFFE, 1998: 113-142. 


\section{GÉNERO, CIUDADANÍA Y GLOBALIZACIÓN}

La falta de una identidad homogénea común no significa, sin embargo, que no se pueda analizar cómo las posiciones de hombres y mujeres se han articulado de modo diferente en las estructuras de poder en que se han desarrollado históricamente. La discriminación de las mujeres como colectivo deriva de que experimentan de modo compartido situaciones de subordinación u opresión que no experimentan los hombres. La percepción y asimilación conjuntas de esa opresión es la que puede articular un discurso emancipatorio compartido, sin el que la emergencia de alternativas a la política o la moral hegemónica resulta imposible. En el caso de la comunidad política, tales discriminaciones derivan de que las mujeres no se identifican con la autoridad política en cuanto se sienten sujetos pasivos, receptoras de prestaciones sociales, y relegadas al ámbito privado. La inclusión democrática de las mujeres no sólo requiere que tengan un papel activo en la construcción cultural de la nación, sino también su identificación con las instituciones políticas comunes, mediante la plena integración en la ciudadanía. Aunque ambos procesos no son independientes. Como afirma BENHABIB, sólo en la medida en que las futuras colectividades posibles, locales, nacionales o globales, se reconstituyan mediante la resignificación democrática de sus legados culturales es factible reimaginar nuevas instituciones de representación, gobierno y participación en el poder ${ }^{22}$.

La historia del feminismo se puede leer en clave de reclamar y construir la ciudadanía ${ }^{23}$. No sólo ha tratado de lograr la incorporación efectiva de las mujeres en lo público, sino de redefinir el sentido y alcance de la ciudadanía en un sentido más inclusivo y participativo. La teoría feminista, en general, ha criticado el carácter abstracto y universalista de la democracia liberal que impide incorporar las experiencias y necesidades de sujetos situados e incardinados en realidades concretas. Su idea de la representación política presupone una idea de bien común o interés general que resulta aceptable para todos los individuos. La dificultad real de alcanzar racionalmente y en abstracto ese ideal en sociedades plurales y complejas deriva de la desigualitaria capacidad de los distintos grupos sociales para incorporar sus problemas y necesidades a la agenda política e intervenir en la toma de decisiones. Las propuestas feministas consisten en construir un nuevo concepto de ciudadanía que atienda a la complejidad social ${ }^{24}$.

Las tesis de una ciudadanía diferenciada se centran en la necesidad de que la organización de lo público reconozca y gestione la diferencia mediante su inclusión en un modelo complejo. Para ello justifican la adopción de mecanismos que compensen el sesgo masculino que imponen los patrones ideológicos y sociales dominantes y permitan una participación real de colectivos marginados, como las mujeres. Entre tales mecanismos se incluyen medidas de acción positiva, representación de grupos, derechos especiales y establecimiento de las condiciones que favorezcan la diversidad

22 BENHABIB, 2006: 297.

23 Agra, 2002.

24 Podrían incluirse en este sentido los estudios, de muy diversa fundamentación, de YEATMAN, 1993; Phillips, 1993; Dean, 1996; Lister, 1999; Mouffe; Yuval-Davis, 1997; Yuval-Davis y Werbner; Young, 2000; y, YOUnG, 2000; BenHabIB, 2004. 
sociocultural. Al discurso de la ciudadanía diferenciada se suman las propuestas de una ciudadanía plural. Mientras que el primero sigue concibiendo la ciudadanía sobre la base del vínculo entre cada individuo y las instituciones políticas compartidas, planteando la necesidad de medidas positivas que refuercen ese vínculo respecto de sujetos marginados, las propuestas pluralistas parten del desbordamiento político de las instituciones vigentes y asumen un modelo multilateral de ciudadanía. Su punto de partida ya no es tanto el de la diferencia de las mujeres sino la fragmentación de la sociedad global y la existencia de plurales ámbitos o sedes de participación. Son éstas segundas propuestas las que tienen especial interés en el actual contexto sociopolítico en el que es urgente la reinvención de lo político en el ámbito transnacional.

Las transformaciones sociopolíticas de nuestro tiempo abren la vía para traer a primer plano el debate sobre las posibilidades de modificar la idea tradicional de ciudadanía y su papel en la agenda global. El concepto tradicional de ciudadanía se ha visto afectado en las últimas décadas por dos elementos relevantes: por una parte, la pérdida de soberanía de los Estados-nación, a los que el concepto se ha vinculado tradicionalmente; y, por otra parte, las múltiples interacciones y redes que traspasan el ámbito global y que generan múltiples pertenencias y adscripciones individuales. El pensamiento feminista se ha planteado las implicaciones que estas transformaciones tienen para las mujeres. Su aportación, en este contexto, es crucial para poder aprovechar los procesos de cambio social para reconfigurar el sentido de las instituciones tradicionales.

El feminismo se suma a quienes rechazan la interpretación neoliberal de la globalización, para la que el desarrollo del capitalismo global es una fase nueva e inevitable de evolución social guiada por una lógica inexorable y tendente a la despolitización de lo público. Por el contrario, trata de mostrar que la globalización económica es un proceso socialmente construido, consecuencia de políticas y acciones plurales que han ido conformando una estructura social compleja y heterogénea, presidida por una lógica pluralista y descentralizada que favorece los procesos autoorganizativos de los agentes y redes con pretensiones e intereses diversos. Este nuevo contexto, fuertemente excluyente y desigualitario, tiene un impacto negativo en el proceso de igualación de hombres y mujeres, que no es un mero efecto o consecuencia de dichas transformaciones sino un cambio que responde a los propios principios estructurales que las guían.

El modo en que afecta a la participación de las mujeres es una cuestión compleja que no puede determinarse a priori ${ }^{25}$. En primer lugar, la globalización no es un proceso uniforme ni unidimensional sino que tiene un impacto distinto en diferentes regiones, grupos o personas. En general, muchos de los factores que producen las consecuencias más negativas de la globalización afectan especialmente a las mujeres que son quienes más sufren su impacto. El fallo de los Estados en la provisión de infraestructura y apoyo social, especialmente de los menos desarrollados que se ven acuciados por un excesivo endeudamiento fruto de la presión global en favor de ajustes estructurales, afecta especialmente a las mujeres, cuya mayor vulnerabilidad en estos Estados se agrava con problemas propios como el turismo sexual, la industria del matrimonio y el sexo o el tráfico internacional de mujeres. Las mujeres de los países pobres son las que

25 Agra Romero, 2006: 67-97. 
soportan la carga más fuerte de la globalización como gestoras de la pobreza, prestadoras de servicios sociales y proveedoras de mano de obra barata y flexible, muchas veces parte de la economía sumergida. Y las emigrantes en países desarrollados son las que desempeñan las tareas menos valoradas y peor remuneradas, situándose muchas veces al margen de la protección incluso formal de los Estados de origen y destino. Estos fenómenos suponen la traslación al ámbito privado de muchas tareas no remuneradas que invisibilizan el coste de las crisis económicas, así como la desregulación, flexibilización y precarización de gran parte del trabajo asalariado, teniendo ambos especial impacto en las mujeres ${ }^{26}$.

Mejorar el status de las mujeres y abrirles oportunidades económicas para que desarrollen sus capacidades ha de ser una parte relevante de cualquier modelo que proponga alternativas a la globalización neoliberal ${ }^{27}$. En este sentido, el feminismo es una de las teorías críticas de la realidad global que más ha insistido en la necesidad de redefinir el concepto de lo político para limitar y controlar la reprivatización de las funciones y espacios asumidos tradicionalmente por el Estado, al tiempo que ha tratado de configurar un concepto de ciudadanía transversal que responda a las necesidades derivadas de las distintas posiciones de los sujetos.

Pero, además, la globalización no afecta por igual a todas las mujeres: es más negativa para las mujeres de los países pobres y para las mujeres marginadas de los países desarrollados (feminismo múltiple y plural). Como señaló M. ${ }^{a}$ MIES, las mujeres no sólo están divididas por diferencias culturales sino fundamentalmente por su situación en la economía global ${ }^{28}$. Por ello, desde la década de los noventa muchas propuestas feministas rechazan el modelo inclusivo, que adopta un modelo universal de sujetomujer culturalmente sesgado y atemporal, y tratan de mostrar las múltiples formas en que el proceso de globalización neoliberal genera desigualdad en condiciones concretas ${ }^{29}$. Se trata de analizar cómo las consecuencias de la liberalización económica y la flexibilización laboral producen efectos determinados en las mujeres en función de su posición y ubicación concretas. Ello supone la necesidad de adaptar la acción política a las necesidades espacio-temporales contingentes, transformándose en posiciones o acciones de resistencia flexibles y condicionadas por el modelo de relaciones de poder en que se desarrollen. Es en la convergencia práctica de esas resistencias donde se puede ir articulando una acción más global.

\subsection{La aportación de un Estado reformado}

Ante el temor a un poder global despolitizado y las dificultades para institucionalizar una democracia global, algunos escritos de mujeres plantean la necesidad de reforzar el poder estatal, defendiendo formas más incluyentes de ciudadanía nacional ${ }^{30}$. Aun

26 SASSEN, 2003.

27 Afshar y Dennis (eds.), 1992; Brodie, 1994: 46-60; JAGGAR; Lister, 1998: 58-59.

28 MIES, 1986.

${ }^{29}$ La base de este análisis se encuentra en las tesis del feminismo posmoderno del tipo de las de BUTLER, 1990; o BRAIDOTTI, 1994, entre otras muchas.

${ }^{30}$ No es ésta una posición unánime en los escritos feministas, muchos de los cuales se cuestionan críticamente el papel de la soberanía estatal, al obstaculizar la participación en la esfera internacional de sujetos 
asumiendo el papel que el Estado ha desempeñado en la ocultación y formalización de la discriminación de las mujeres, puede pensarse que mientras no sea posible instituir un orden global que regule las interacciones transnacionales y organice el poder global garantizando los derechos, el Estado tiene aún mucho que decir ${ }^{31}$. La pertenencia a un Estado y la titularidad de derechos reconocidos y garantizados por un ordenamiento estatal eficaz es ahora más, y no menos, importante, puesto que, a falta de alternativas reales, la crisis del Estado supone la pérdida de instrumentos de garantía y de responsabilidad política. Especialmente en el caso de las mujeres, en el que la crisis del Estado contribuye a minar los logros sociales alcanzados.

Es por ello que el potencial garantista del Estado debe obligarle a buscar en el proceso de transnacionalización aquellos elementos que le permitan aumentar su poder de acción y dirigir la actuación del resto de actores. El Estado debe aprovechar los instrumentos y estrategias de su relación con actores no estatales para aumentar su legitimidad y capacidad de ejecución de sus políticas, al tiempo que le corresponde supervisar y dirigir las relaciones de gobernanza, estableciendo fines, proveyendo recursos administrativos y normativos, garantizando su ejecución y legitimando su actuación ${ }^{32}$. Ello exige una reformulación del propio concepto de legitimidad estatal conforme a la que la legitimidad interna del Estado es inescindible de la justificación de su actuación exterior o respecto de los extraños en el interior, planteando la separación entre Estado y democracia global no tanto como una dicotomía sino como un continuo que obedece a un proyecto común. En él, las instituciones supraestatales refuerzan y expanden algunas de las dimensiones de las democracias estatales.

La reformulación del concepto de legitimidad estatal implica un cambio relevante en la concepción de la distinción entre miembros y no miembros. Un modelo de justicia global debe ser compatible con el modelo teórico-político estatal, lo que implica que la asignación de derechos, deberes o prohibiciones que cualquier agente global (Estados, empresas, asociaciones, ONGs, etc.) hace a los no miembros debe ser consistente con el modo en que los asigna a sus miembros ${ }^{33}$. Frente a la exclusión de lo externo o ajeno se reclama una percepción de la interdependencia global y la consideración de cualquier violación de derechos o injusticia social como un problema propio de cualquier agente global. Ello supone un cambio esencial en el modo de concebir las fronteras, no ya como barrera impermeable de exclusión cuanto como instrumentos para un reparto eficiente de competencias permeable a la comunicación y la distribución.

Este Estado reformado debería cambiar su actitud respecto de los no miembros que pretenden incorporarse legítimamente en su ordenamiento. La multitud de causas que generan en nuestros días que millones de personas se desplacen involuntariamente de sus comunidades de origen (el auge demográfico, la creciente urbanización, la crisis alimentaria, la escasez de agua, la destrucción del medio ambiente, las catástrofes naturales relacionadas con el cambio climático, las guerras y otros conflictos violentos, el paro, el empobrecimiento, etc.) obliga a redefinir el concepto de las migraciones

distintos del Estado, considerando que es precisamente la pérdida de poder a nivel nacional la que abre posibilidades a nuevas formas de hacer política, desde lo local a lo global (vid. SASSEN, 2003: 78 y ss.; KNOP, 2002).

31 En este sentido, PetTman, 1999: 207-220.

32 Bell y HindMOOR, 2009.

33 Caney, 2005: 65, nota 7. 
y la condición de asilado y refugiado. Tal redefinición debe ampliar su contenido de obligaciones públicas y derechos individuales de forma que se convierta en un instrumento de garantía de la dignidad personal ante una variedad de causas que generan situaciones individuales sumamente dramáticas.

En este sentido, el Estado no debería, por ejemplo, rechazar el asilo por razones de respeto a la soberanía estatal o a la especificidad cultural a las mujeres que huyen de sus países por el riesgo que sufren de violaciones a su integridad personal, tales como las persecuciones sufridas por las mujeres en Irán o Afganistán, o las de las mujeres que tratan de escapar de las duras políticas demográficas chinas o la mutilación genital en los países del África occidental ${ }^{34}$. El derecho de asilo es un instrumento normativo que el Estado puede emplear para garantizar la protección de personas que no son miembros, favoreciendo que cualquier persona pueda disfrutar de un entorno pacífico y promoviendo su integración social. La realidad de la violencia ejercida contra las mujeres requiere ser atendida como causa de persecución a los efectos de obtener la condición de asilado en el territorio de un Estado distinto de aquel en que se sufre la violencia ${ }^{35}$. Existe persecución por motivos de género cuando la violación de derechos de una persona se produce por su pertenencia a un sexo, lo que tiene lugar en mayor medida respecto de las mujeres que, en muchos casos, parten de una situación de desigualdad o subordinación que se manifiesta en acciones tales como la mutilación genital, trata de personas para la prostitución o explotación sexual, violencia doméstica, violación y abusos sexuales como arma de guerra, crímenes de honor, etc. La tendencia de los Estados europeos a conceder el asilo en supuestos de violencia contra las mujeres de comienzos de este siglo ${ }^{36}$ ha ido descendiendo en los últimos años en los que los Estados de la Unión Europea están adoptando políticas de control migratorio que dificultan el acceso a las vías de solicitud de protección internacional de quienes sufren violencia en otros Estados, lo que supone una dejación de su responsabilidad en la colaboración y cooperación para la promoción de un orden global más justo.

34 Vid. ВНАВНА, 178-191.

35 España ha regulado de modo explícito la persecución por motivos de género como causa para justificar el asilo, haciendo una interpretación evolutiva de las Directrices del ACNUR, en la disposición adicional vigésima novena de la Ley Orgánica 3/2007, de 22 de marzo, para la igualdad efectiva de mujeres y hombres, que reforma la ley reguladora del derecho de asilo, y la Ley 12/2009, de 30 de octubre, reguladora del derecho de asilo y de la protección subsidiaria. También el art. 31 bis de la Ley Orgánica 4/2000, de 11 de enero, sobre derechos y libertades de los extranjeros en España y su integración social (reforma de la Ley Orgánica 2/2009, de 11 de diciembre) regula medidas en beneficio de mujeres extranjeras víctimas de violencia de género. Cualquiera que sea su situación administrativa, se les garantizan los derechos reconocidos en la Ley de Medidas de Protección Integral contra la Violencia de Género y las medidas de protección y seguridad establecidas en la legislación vigente, además de la suspensión del expediente administrativo sancionador, si están en situación irregular, y la posibilidad de solicitar una autorización de residencia y trabajo por circunstancias excepcionales.

36 España ha venido concediendo el asilo a mujeres víctimas de violencia desde 2005 y nuestros tribunales han reconocido en varias ocasiones la persecución por razón de sexo como causa para conceder el asilo (vid. las sentencias de la Audiencia Nacional de 13 de enero de 2009 y las sentencias del Tribunal Supremo de 15 de febrero de 2007, 11 de mayo de 2009 y 15 de junio de 2011). En ellas el alto tribunal afirma que «en aquellos supuestos en que se acredite la existencia de «indicios suficientes», según las circunstancias de cada caso, de que una mujer sufre persecución por su pertenencia al género femenino, que le ha supuesto la imposición de prácticas contrarias a la dignidad humana, como el matrimonio forzoso o la mutilación de un órgano genital, y que el régimen legal del país de origen no ofrece una protección jurídica eficaz, procede la concesión del derecho de asilo...» (FJ 4. ${ }^{\circ}$ de la STS 4013/2011, de 15 de junio). 
Sin embargo, las razones en favor del otorgamiento del asilo o la condición de refugiado no pueden sostenerse sólo sobre la base de un derecho de acceso o visita limitado sino que deben servir igualmente para favorecer la transición hacia la incorporación y la pertenencia a la sociedad política receptora ${ }^{37}$. Además, la necesidad del otorgamiento del asilo o la condición de refugiado, así como de políticas migratorias protectoras y garantistas, deriva de que en los Estados de origen no se dan las condiciones políticas y sociales que permitan ofrecer una protección eficaz de la dignidad de cualquier ser humano y, al mismo tiempo, de que las causas de ese fracaso no son sólo de carácter interno. Las cuestiones de justicia que plantean las migraciones y desplazamientos involuntarios son, en muchos casos, la consecuencia de una estructura global tremendamente injusta cuya modificación compromete moralmente a todos los agentes que participan en la misma. En su mayor parte, las personas desplazadas lo que pretenden es la reforma de las estructuras jurídicas, políticas, económicas y técnicas de sus propios Estados que les permitan desarrollar en éstos sus planes de vida. Pero, mientras perduren Estados desestructurados y no exista una estructura institucional distributiva global que sea adecuada y efectiva, los Estados no pueden rehuir sus obligaciones respecto de los desplazados ${ }^{38}$. El fin ha de ser, no obstante, la justicia global, la superación de la antítesis entre lo interno y lo externo.

\subsection{Concepción plural de la ciudadanía}

Todo lo anterior implica la necesidad de desarrollar un concepto ampliado o diversificado de ciudadanía, en el que la participación y los derechos de los individuos no dependan de la voluntad de los Estados; una ciudadanía «posnacional» o «desnacionalizada» construida como participación en espacios alternativos que contribuyan a hacer efectivos los derechos. En general, gran parte de los escritos feministas de las últimas décadas han teorizado, desde premisas diversas, acerca de un modelo de ciudadanía que abarque la diversidad social. Las propuestas más críticas no consisten meramente en sustituir la ciudadanía nacional por una ciudadanía supranacional o cosmopolita con base en instituciones internacionales, sino en la construcción de escenarios políticos transversales que permitan una gama amplia de intervenciones. Tales propuestas van más allá de las exigencias de igualdad e inclusión del feminismo liberal y de las exigencias de diferenciación y el planteamiento de modelos feminizados de las corrientes de la diferencia, y parten de un tercer modelo para el que tanto hombres como mujeres tienen múltiples identidades y adscripciones desde las que deben plantear sus demandas y reivindicaciones. Se piensa que las actuales transformaciones en la construcción tradicional de la ciudadanía abren posibilidades para la emergencia de nuevos espacios formales e informales de participación política y la incorporación de nuevos problemas a los mismos, contribuyendo ambas tendencias a la inclusión efectiva, y no sólo formal, de sectores desfavorecidos.

La ciudadanía nacional y supranacional, así como otros modelos más informales de participación, se conciben como dos modalidades coexistentes e interrelacionadas

\footnotetext{
37 En este sentido, BENHABIB, 2001: 31 y ss.

38 En este sentido, BADER, 1997: 1-11.
} 
de un modelo genérico de ciudadanía ${ }^{39}$. Conforme a éste, los sujetos políticos están inmersos en una pluralidad de posiciones y comunidades que se extienden dentro, a través de o más allá de las fronteras estatales y desean que cualquier construcción global les reconozca y respete en tales posiciones particulares. Pero las diferentes posiciones sociales no pueden incorporarse como identidades completas y cerradas, sino en su complejidad y heterogeneidad, mediante un proceso de encuentro y conversación gradual que expanda la perspectiva de cada uno hacia «los otros». El resultado es un modelo en el que la negación de la separación sustantiva entre lo privado y lo público significa que la esfera pública no está constituida por sedes o espacios específicos, sino que existen tantos espacios públicos como debates sobre una pluralidad de asuntos normativos conflictivos.

A estas premisas responden las propuestas feministas de concepciones plurales de la ciudadanía, como el modelo de ciudadanía multinivel de N. YUvAL-DAvIS, que opera en múltiples ámbitos de lo local a lo global en los que las personas pueden expresar múltiples lealtades e identidades solapadas que responden a necesidades y contextos históricos diferentes ${ }^{40}$. En él, el nivel local de las asociaciones o la ciudad y el nivel de las instituciones supranacionales pueden ayudar a suplir las insuficiencias en el disfrute efectivo de la autonomía de la mujer que no logran las estructuras sociales y económicas estatales. Se trata de que las mujeres, y otros actores hasta ahora invisibilizados en el Estado, puedan aprovechar todos los espacios de participación y reivindicación.

En el modelo multinivel de ciudadanía, la pertenencia de las personas a un Estado, sus derechos y responsabilidades, están mediadas por su pertenencia a otras colectividades, subestatales, transversales o supraestatales. Su posición en estas otras comunidades, así como en términos de clase, género, tendencia sexual, edad, capacidad, etc., debe tenerse en cuenta en cualquier proyecto de ciudadanía que pretenda ser inclusivo y democrático. La propuesta de YUVAL-DAVIS es una ciudadanía transversal de diálogo que parta del reconocimiento y empatía con las posiciones específicas que ocupan quienes participan en el mismo: la cooperación y solidaridad entre feministas situadas en posiciones diferentes debería estar informada por esas experiencias diferenciadas ${ }^{41}$. La participación en la ciudadanía no se realiza desde la identificación acrítica con una identidad grupal única, sino que cada participante contribuye con su experiencia particular para tratar de cooperar y negociar con quienes parten de una pertenencia diferente. El diálogo tiene por objeto lograr una perspectiva común basada en un sistema de valores compatible con los posicionamientos plurales. Desde esta perspectiva, la ciudadanía nacional ha de verse afectada por los posicionamientos de los individuos en otras colectividades, que pueden ser el recurso para hacer que las capacidades de los individuos sean efectivas.

Esta noción de ciudadanía incorpora la acción privada, esto es, la actividad de las asociaciones, movimientos sociales, redes de intereses, actos de protesta, renuentes o incapacitados para identificarse con las instituciones públicas. El resultado es

39 WERBNER y YUVAL-DAVIS, Introducción a YUVAL-DAVIS y WerbNER 1999: 3.

40 YuVAL-DaVIS, 1999: 119-136.

41 N. Yuval habla de «universalidad en la diversidad», que pretende superar la dicotomía entre universalismo — que asume un punto de partida homogéneo—y relativismo — que considera que, dadas las diferencias en los puntos de partida, no es posible un diálogo genuino y crítico- (YuvaL-Davis, 1997: 125). 
que esta perspectiva plural convierte el concepto de ciudadanía para el feminismo en un instrumento útil para lograr una acción solidaria y colectivamente responsable. S. SASSEN piensa que la reconceptualización de la ciudadanía en este sentido desvía su naturaleza desde sus aspectos jurídico-formales hacia acciones efectivas de afirmación de intereses y aspiraciones que van más allá de las normativas estatales. Para la autora, la ciudadanía se crea en parte a través de las prácticas de los excluidos, en la medida en que las profundas transformaciones sufridas por el Estado ante la globalización reducen sus posibilidades para emprender una nueva ampliación jurídica que conduzca a nuevas inclusiones de sujetos o derechos. Este concepto más empírico o práctico de ciudadanía permitiría cubrir la distancia que media entre la ciudadanía formalizada en los ordenamientos vigentes y la experiencia ciudadana de sujetos excluidos de aquella pero activos en la reclamación de sus intereses y necesidades (tales como los inmigrantes indocumentados, los no asalariados, las amas de casa, etc.). De este modo, los desfavorecidos adquieren presencia en el proceso político más allá de los límites del ordenamiento formal ${ }^{42}$.

El discurso de la ciudadanía multinivel o transversal y la ciudadanía desnacionalizada ha resultado especialmente atractivo para el feminismo en las últimas décadas, en cuanto que, por una parte, aboga por una multiplicidad de marcos políticos que permite evitar cualquier forma de exclusión social o política y, por otra, permite introducir en el debate político la perspectiva y los problemas de las mujeres. La reflexión teórica y metodológica pluralista, como se ha afirmado, ha posibilitado que «voces otras veces marginadas puedan ser oídas; que cuestiones en otras ocasiones suprimidas puedan ser escuchadas; que espacios cerrados para el análisis se han abierto al debate; que cuestiones de hecho descartadas de la aproximación dominante pueden ser seriamente reconsideradas y reevaluadas» ${ }^{43}$. El feminismo se une, así, a otras posiciones críticas que asumen concepciones teóricas pluralistas como base para articular un modelo que capacite a los colectivos marginados. Además, este concepto de ciudadanía permite sustituir el discurso feminista esencialista o identitario por un discurso contextual para el que el sentido de una acción global de las mujeres es el de plantear los problemas que las mujeres comparten en todo el planeta, tales como la salud reproductiva, la violencia machista, la desigualdad laboral y salarial, la precarización del trabajo o la pobreza, lo que puede hacerse desde localizaciones concretas.

A pesar de su valor práctico para incorporar la pluralidad, los modelos socio-políticos pluralistas, presididos por una lógica flexible y descentralizada, resultan criticables en sus presupuestos relativistas y su escepticismo institucional. Los propios presupuestos pluralistas implican que la ciudadanía no puede ofrecer un criterio universal en el que fundar la crítica de los sujetos o grupos marginados. Lo que tiene consecuencias políticas: la ciudadanía plural parte de una noción de autoridad desjerarquizada en la que los diversos espacios de participación se solapan e interactúan, postulando el mutuo reconocimiento e igual respeto a todas las pretensiones e intereses, en cuanto que se consideran inconmensurables. Al margen de los problemas de organización de las diversas redes y ámbitos de discusión, este particularismo posmoderno disuelve el modelo tradicional de autoridad legal en una pluralidad de agentes y ámbitos participa-

\footnotetext{
42 SASSEN, 2003: 87-113.

43 GeORGE, 1993: 272-273.
} 
tivos. Del diálogo y la negociación efectivos, dependientes de las circunstancias específicas de cada contexto, deriva la fundamentación de las decisiones sociales y políticas. Su legitimidad se hace depender de los propios principios formales de autodeterminación e igual participación al margen de la fundamentación material de las decisiones ${ }^{44}$.

Creo, sin embargo, que el ejercicio por las mujeres de su capacidad de participación no es independiente de la necesidad de formalizar sus derechos e institucionalizar las garantías correspondientes. Los límites institucionales no sólo suponen restricciones sino también habilitaciones para actuar como ciudadanas. Ciertamente, como señalan los modelos de ciudadanía transversal o desnacionalizada, los límites de la actividad política y los límites de la estructura institucional estatal no pueden ya ser considerados coextensivos, dada la necesidad de ampliar la dimensión práctica de la ciudadanía por debajo y más allá de las fronteras del Estado. Pero la ciudadanía no tiene sólo que ver con la participación sino también con el status y la pertenencia formal. El fin de las prácticas informales de ciudadanía no puede agotarse en actos de protesta o victimización sino que debe tender a la formalización de nuevos tipos de sujetos políticos y de nuevos derechos que incorporen las demandas y necesidades antes marginadas. En este sentido, aquellos movimientos y dinámicas pueden concebirse como elementos para el cambio y la innovación institucional.

Las críticas al sistema de partidos y los modelos de democracia post-representativa relativizan el papel de las instituciones democráticas, a las que consideran sólo una de las partes posibles de un proceso de formación de la voluntad colectiva más amplio. Pero la organización de la diversidad exige que tales instituciones articulen las plurales demandas sociales y las transformen en decisiones colectivas, exige que ejerzan de mediadoras entre los valores e intereses en conflicto. La satisfacción plena y simultánea de los intereses y aspiraciones de unos es incompatible con la atención plena a las necesidades de otros. El pluralismo es insuficiente si no hay una integración común en sistemas que organicen la diversidad. Por ello, la atención a la pluralidad no puede traducirse en una pura estrategia de coexistencia sino que debe tender a una gradual convergencia práctica y promoción de valores públicos compartidos.

\section{BIBLIOGRAFÍA CITADA}

Afshar, H., 1994: «Women and the Politics of Fundamentalism in Iran», Women against Fundamentalism Journal, núm. 5, 15-21.

Afshar, H., y Dennis, C. (eds.), 1992: Women and Structural Adjustment Policies in the Third World, London: Macmillan.

Agra, M. X., 2002: «Ciudadanía. El debate feminista», en F. QuesAdA (ed.), Naturaleza y sentido de la ciudadanía hoy, Madrid: Publicaciones UNED.

— 2006: «Ciudadanía, feminismo y globalización», en A. Rubio CASTRO y J. HeRrera (coords.), Lo público y lo privado en el contexto de la globalización, Sevilla: Instituto Andaluz de la Mujer, 67-97.

${ }_{44}$ R. Voet afirmaba que, en lugar de considerar la ciudadanía como el medio para la satisfacción de los derechos, debemos considerar los derechos como un medio para realizar la igual ciudadanía; lo que significa que el feminismo debería ser, más que un movimiento en favor de los derechos de las mujeres, un movimiento en favor de la participación de las mujeres (VOET, 1998: 73). 
Ahmed, L., 1984: «Early Feminist Movements in Turkey and Egypt», en F. Hussain (ed.), Muslim Women, London: Croom Helm.

Appiah, K. A., 2005: La ética de la identidad, Buenos Aires: Katz.

BADER, V. (ed.), 1997: Citizenship and Exclusion, Houndsmills: MacMillan Press.

Bell, S., y Hindmoor, A., 2009: Rethinking Governance. The Centrality of the State in Modern Society, Cambridge: Cambridge University Press.

Benhabib, S., 2001: Transformations of Citizenship. Dilemmas of the Nation State in the Era of Globalization, Koninklijke Van Gorcum.

- 2004: Los derechos de los otros, Barcelona: Gedisa.

- 2006: Las reivindicaciones de la cultura. Igualdad y diversidad en la era global, Buenos Aires: Katz.

BнAвHA, H. (ed.), 1990: Nation and Narration, London: Routledge.

- 1994: The Location of Culture, London: Routledge.

BRAIDOTTI, R., 1994: Nomadic Subjects: Embodiment and Sexual Difference in Contemporary Feminist Theory, New York: Columbia.

Brodie, J., 1994: «Shifting the Boundaries: Gender and the Politics of Restructuring», en I. BAKKer (ed.), The Strategic Silence: Gender and Economic Policy, London: Zed Books, 46-60.

Buss, D., y MAnj, A. (eds.), 2005: International Law. Modern Feminist Approaches, Oxford: Hart Publishing.

ButLer, J., 1990: Gender trouble: Feminism and the subversion of identity, New York: Routledge.

Caney, S., 2005: Justice beyond Borders. A Global Political Theory, Oxford: Oxford University Press.

Charlesworth, H., y Chinkin, Ch., 2000: The Boundaries of International Law: A Feminist Analysis, Manchester: Manchester University Press.

FrASER, N., 2005: «Redefiniendo el concepto de justicia en un mundo globalizado», en Anales de la Cátedra de Francisco Suárez, Granada.

GEORGE, J., 1993: «International Relations and the Search for Thinking Space: Another View of the Third Debate», International Studies Quarterly, vol. 33, núm. 3 (septiembre).

Gouges, O. DE, 1791: Epílogo a Declaración de los derechos de la mujer y de la ciudadana.

IsIn, E. F., y WoOD, P. K., 1999: Citizenship and Identity, London: Sage.

JAGGAR, A., 1998: «Globalizing Feminist Ethics», Hypatia, vol. 13, núm. 2, 7-31.

JaYAWARDENA, K., 1986: Feminism and Nationalism in the Third World, London: Zed Press.

KANDIYOTI, D., 1991: «Identity and its Discontents: Women and the Nation», Millenium. Journal of International Studies, vol. 20, núm. 3, 429-443.

KNOP, K., 2002: Diversity and Self-Determination in International Law, Cambridge: Cambridge University Press.

Koskenniemi, M., 2005: From Apology to Utopia. The Structure of International Legal Argument, Cambridge: Cambridge University Press, reed.

— 2007: «The Fate of Public International Law: Between Technique and Politics», The Modern Law Review, vol. 70, núm. 1, enero, 1-30.

Lister, R., 1997: Citizenship. Feminist Perspectives, London: MacMillan.

Mernissi, F., 1985: Beyond the Veil, London: Al Saqi Books.

Mies, M., 1986: Patriarchy and Accumulation on a World Scale, London: Zed Books.

OfFE, C., 1998: «"Homogeneity" and Constitutional Democracy: Coping with Identity Conflicts through Group Rights», Journal of Political Philosopby, vol. 6, núm. 2, 113-142. 
Phillips, A., 1993: Democracy and Difference, Oxford: Polity Press, 1993; Dean, J., 1996: Solidarity of Strangers, Berkeley: University of California Press.

SAADAWI, N. El, 1988: «The Political Challenges Facing Arab Women at the End of the 20th Century», en N. Toubia (ed.), Women of the Arab World, London: Zed Press.

SASSEN, S., 2003: Contrageografías de la globalización. Género y ciudadanía en los circuitos transfronterizos, Madrid: Traficantes de Sueños.

Simmel, G., 1977: Sociología. Estudios sobre las formas de socialización, Madrid: Revista de Occidente.

TAMZALI, W., 2011: Carta de una mujer indignada. Desde el Magreb a Europa, Madrid: Ediciones Cátedra-Universitat de València-Instituto de la Mujer.

VOET, R., 1998: Feminism and Citizenship, London: Sage.

WalBY, S., 1992: «Woman and Nation», International Journal of Comparative Sociology, 33, núms. 1-2.

WesT, L. A., 1997: «Introduction: Feminism Constructs Nationalism», en L. A. WeST (ed.), Feminist Nationalism, New York: Routledge, xi-xxxvi.

Woolf, V., 1980: Tres Guineas, Barcelona: Lumen.

Yeatman, A., 1993: Post-Modern Revisionings of the Political, London: Routledge.

YounG, I. M., 2000: La justicia y la politica de la diferencia, Madrid: Cátedra.

- 2000: Inclusion and Democracy, Oxford University Press.

Yuval-Davis, N., 1997: Gender and Nation, London: Sage Publications.

— 1999: «The "Multi-Layered Citizen". Citizenship in the Age of Globalization», International Feminist Journal of Politics, vol. 1, núm. 1, 119-136.

Yuval-Davis, N., y Werbner, P. (eds.), 1999: Women, Citizenship and Difference, London: Zed Books. 